\title{
Nova edição da Comédia, de Dante
}

Marco Lucchesi

$\mathrm{O}_{\mathrm{s}}$

ESTUDO da obra de Dante em língua portuguesa forma, por densidade e extensão, um ramo de não pequeno relevo no campo de interesse dos dantólogos. E pode se dividir em duas fases, antes e depois de Machado de Assis, de quem se esperava, aliás, a tradução completa da Comédia, que havia de ser magistral, a julgar pela tradução feita por Machado do canto 25 do Inferno. O melhor do que nos legou o Segundo Reinado, além das releituras de Dante esparsas nas páginas machadianas, desfeitas ou mesmo transformadas, como em "O alienista": "la bocca sollevò dal fiero pasto, quel seccator". Antes de Machado, comparece na poesia dos poetas coloniais, que ou realizam translatos da obra dantesca, ou multiplicam citações, absorvendo-lhe o cenário e alguma temperatura, como Manoel de Santa Itaparica em Estáquidos, ou nas harmonias celestiais do Caramuru, de Santa Rita Durão, onde surge um Dante-Camões, entre o canto 10 de Os lusiadas e o 33 do Paraíso. A máquina do mundo e o livro de Deus. Era sempre a Comédia que fazia parte do acervo da Companhia de Jesus e dos monges beneditinos, cujo primeiro exemplar do poema sacro - segundo Câmara Cascudo - teria chegado já no século XVII.

A forma do velho e grave florentino, entretanto, aumentaria consideravelmente apenas no século XIX. O "Inferno" parecia adequar-se ao prefácio de Cromwell, de Victor Hugo. Olhos contrastivos. Uma pluralidade de nomes e episódios combinados iam minando a poderosa unidade da Comédia. Donde os

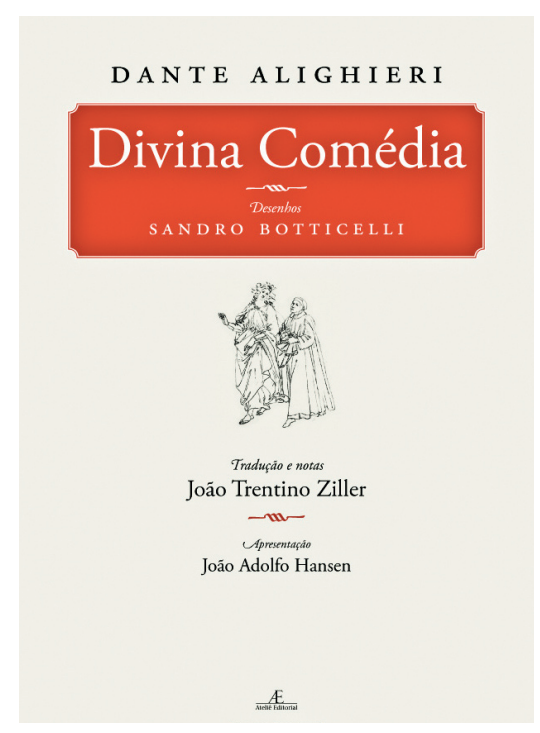

ALIGHIERI, D. Divina comédia. Trad. João Tretino Ziller. Ilust. Sandro Botticelli.

São Paulo: Ateliê, 2011. 560p.

(Col. Clássicos Comentados).

virgílios e as beatrizes, as francescas e os ugolinos de que se alimentam as citações de Gonçalves Dias, Álvares de Azevedo e Bernardo Guimarães. Mais profunda, a permanência de "O navio negreiro", de cujas águas emergem paráfrases admiráveis do canto 3 do "Inferno".

Também a prosa brasileira do século XIX é marcada pelas citações diretas ou indiretas de Dante. Penso em Nabuco. Em Rui. E volto a Machado - primus inter pares - que inspirou Xavier Pinheiro a realizar a primeira tradução integral da Commedia em terza rima, depois da leitura daquele mesmo canto 25 do Inferno, da metamorfose, dos ladrões, publicado em 1874. 
Desde então, contamos no Brasil com um grande número de edições parciais da Comédia e da lírica, em prosa, em versos brancos, em versos de martelo e bigorna, ou em formas suaves e cheias de harmonia. Como não destacar as claras traduções de Dante Milano do "Inferno", e as de Henriqueta Lisboa do "Purgatório", e as de Haroldo de Campos do "Paraíso". Ou do grande Jorge de Lima, incorporando - em Invenção de Orfeu - partes inteiras da tradução de Xavier Pinheiro! Jorge de Lima, depois de Machado, foi quem melhor compreendeu Dante no Brasil. Last but not the least, Cristiano Martins, poeta rilkiano, que nos deu a melhor - até agora - tradução integral da Comédia, que rivaliza, a meu ver, com a de Vasco Graça Moura, publicada em 1996 em Portugal. E para encerrar essa longa excursão, seria preciso anotar a tradução de Italo Eugenio Mauro, com seus altos e baixos, e o projeto inacabado, de Jorge Wanderley, que não passou do Inferno e por uma árdua ausência biográfica. Louvável naquela edição as notas frondosas que abrangem uma história e uma poética de Dante em nossa língua.

A tradução de João Trentino Ziller, reeditada pela Ateliê Editorial, faz parte dessa espessa lusosfera. Trata-se de edição monumental, com lúcido prefácio de João Adolfo Hansen, amigo do padre Vieira, além do estudo de Henrique Xavier sobre Botticelli: existe vida fora em Dante mesmo sem Gustave Doré! A leitura de Botticelli guarda um fascínio insuperável, nas imagens críticas do Inferno ou nas translúcidas do Paraíso.

A presente obra de Ziller, italiano de origem, que se aprofundou na língua de Camões e Virgílio, mostrou-se altamente sensível aos apelos do mistério e da poesia. Traduziu Dante como se buscasse uma forma de expressão identitária, como um De Simone, no Segundo Reinado, ou do mais recente Italo Eugenio Mauro. Ziller guarda proximidade maior com esse, no sentido de que ambos realizaram a circunavegação da Commedia, depois dos setenta anos. E é um testemunho comovente de afeto e ousadia.

A obra apresenta inúmeros pontos de contato com acertos históricos e desvios. Salta aos olhos uma liberdade relativa dos pés e das variantes do decassílabo, sem que se evite, em alguns casos, o diabolus do acento na quinta sílaba. Há um fio musical, todavia, que organiza as escolhas, por assim dizer, heterodoxas, motivadas pela manutenção do esquema rímico, o que merece aplauso. Mas a rima não é um norte exclusivo. O tradutor deixa de lado algumas vezes o polo magnético das aliterações, realizando supressões que dissolvem um coágulo de sílabas, ou que não atendem às redundâncias do original. É o duro ofício da tradução, de ganhos e perdas. Ziller não quis que o conteúdo se perdesse. E se pautou pela rima e pelo fio narrativo.

E nisso a nova edição da Comédia integra-se nas falhas e acertos de nossa tradição. A rima em Dante implica um tratado complexo, e quando se transportam para outras línguas, esquecem os tradutores que não se deve clarear o que no original é escuro ou vice-versa, apagando-se no texto de chegada o que é áspero e duro, das palavras infames, que desaparecem na tradução, ou dos notáveis neologismos, que parecem esmaecidos e bem comportados, longe da alta voltagem do texto de partida.

Sente-se, no trabalho meritório de Ziller, um sotaque de quem conviveu com os clássicos, sobretudo com a Eneida. Um 


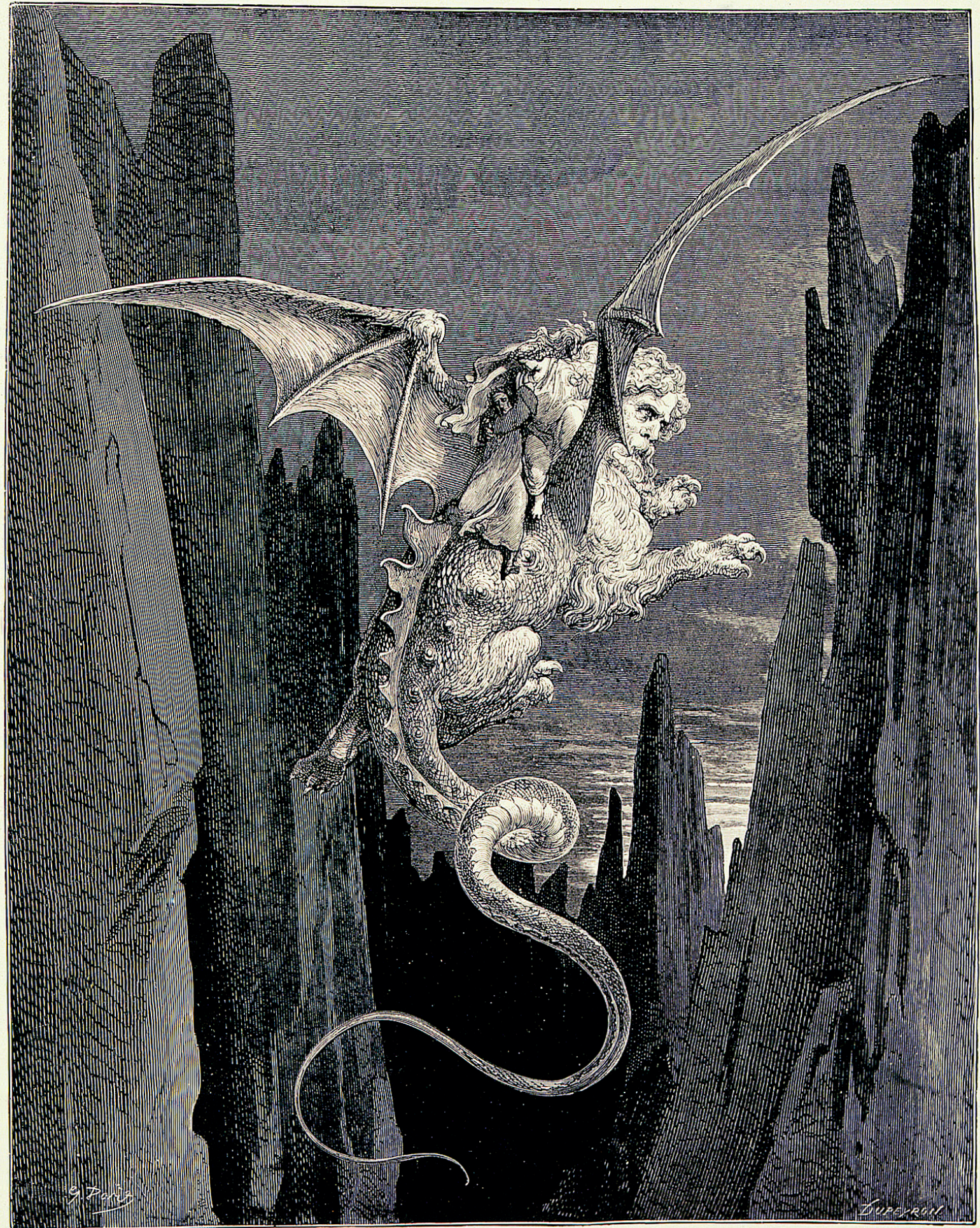

Ilustração de edição de 1860 de A divina comédia, de Dante Alighieri. 
grau interessante de intertexto emerge com elegância de seu trabalho, sobretudo no Inferno e no primeiro canto do Purgatório, o que valoriza e justifica esta edição.

Outro aspecto reiterado das traduções em nossa língua repousa na chuva torrencial de advérbios, que não aparecem no original, para encompridar, no verso, a diferença de aféreses e de epênteses entre o português e o italiano, com fortes inversões estruturais e grande quantidade de rimas no infinitivo ou no particípio passado.

O que mais prezo na tradução de Ziller é que o fato de ele ter seguido em Dante uma espécie de princípio Horus, ou seja, uma trama luminosa, que tece o princípio arquitetônico da obra ou o flatus poético que os pulmões do tradutor não podem deixar de respirar. O que Ziller sentiu foi o ritmo, o batimento cardíaco do poema. E nisso reside seu mérito, a sua demanda biográfica na viagem para Beatriz, passando por Francesca da Rimini e Pia dei Tolomei, num ensaio de mudanças.

A tradução como a práxis da mudança ou da metamorfose. A mesma que Machado realizou em seu ofício, abrindo uma longa estrada para Dante em nosso meio.

Marco Lucchesi é escritor, professor da Universidade Federal do Rio de Janeiro (UFRJ) e membro da Academia Brasileira de Letras (ABL).

@ - marcolucchesi@terra.com.br 